\title{
EL VOYEUR EN LA LITERATURA DEL SIGLO XX
}

\section{Carolina Sanabria}

\begin{abstract}
RESUMEN
El presente artículo analiza las relaciones entre la literatura y la imagen visual desde la actividad del voyeur. El punto de partida es que la literatura, contrario al enfoque que la privilegia como operación sublimada de un creador mitificado, supone una intromisión extraña (del narrador y del lector) en un entorno ajeno aun cuando se trate de personajes de ficción. El esclarecimiento habría podido ser constatado a partir del desarrollo y consolidación de los medios de comunicación de masa, en particular el cine. Bajo este tamiz, se analizan dos obras literarias significativamente contemporáneas -El mirón (Le voyeur, 1952) de Robbe-Grillet y El hombre que mira (L'uomo che guarda, 1985) de Alberto Moravia- que desde el enfoque fenomenológico y el freudiano respectivamente evidencian la figura del voyeur y sus mecanismos de construcción en la literatura universal.
\end{abstract}

Palabras clave: Lector, voyeur, espectador, protagonista, narrador.

\begin{abstract}
This article analyses the relations between literature and the visual image from the voyeur's activity. The departure point is that literature, contrary to the approach that places it as sublimated operation of a mythified creator, supposes a strange intromission (from the narrator and reader) in a strange surrounding though it may be dealing fictitious characters. The clarification could have been verified from the development and consolidation of the mass media, and movies to be more specific. Through this sieve, we analyse two contemporary literary works -Le voyeur, 1952 written by Robbe-Grillet, and L'uomo che guarda (The man who looks, 1985) by Alberto Moravia- that from the phenomenological and Freudian approaches show the voyeur figure and his construction means in the universal literature.
\end{abstract}

Key words: Reader, voyeur, spectator, protagonist, narrator.

Carolina Sanabria. Doctora en Comunicación Audiovisual, Universidad Autónoma de Barcelona. Profesora de la Escuela de Estudios Generales, Universidad de Costa Rica. San Pedro, San José, Costa Rica.

Correo electrónico: csanabriacr@yahoo.com

Recepción: 12-11- 2007

Aceptación: 10-1- 2008 


\section{La visualización literaria: boceto. Crítica y producción general}

La fenomenología misma de cualquier género de ficción remite invariablemente a un sustrato voyeur, dado que lo que está siempre en cuestión es el relato de una circunstancia ajena al lector en la que toman parte unos personajes igualmente ajenos. El hecho resulta particularmente ejemplar en la novelística policíaca, caracterizada por consolidar una figura que vehicula, que personaliza con mayor claridad que en cualquier otro tipo de narrativas, la relación del lector (como voyeur) con respecto a la diégesis: el detective ${ }^{1}$. Josep Maria Català, refiriéndose a los escritos de Edgar Allan Poe, plantea que el lector se introduce en la narración a partir de un punto de vista que se ubica "por encima del hombro" del detective, compartiendo, más que una perspectiva, una situación análoga a su acto de ver y una conversión en el doble etéreo del personaje (1997: 190), de manera tal que termina reafirmándose como una presencia extraña al texto ${ }^{2}$.

Es probable que tal constatación difícilmente no haya podido vislumbrarse hasta este momento de desarrollo audiovisual. Nada más lejos que constituir un fenómeno reciente, pero los antecedentes del siglo XIX, cuando "la literatura narrativa es fa visual. Oblida el desenrotllament del concepte per esdevenir retinal" (Fanés 1985: 28), abonan una mayor liberación de presiones representativas y de formación audiovisual que da lugar a una nueva proclividad visual expresada en el texto límite: obsceno, violento, baboso ${ }^{3}$.

Sin que se ponga en duda la vigencia de la cultura escrita, esta "ha cedido territorio a las nuevas formas de cultura oral e icónica, estrechamente vinculadas a la abrumadora hegemonía de los medios de comunicación audiovisuales en la escena cultural contemporánea" (Chillón 1999: 63). Su materia prima, la imagen, cuya transacción a la palabra se venía realizando, aunque imperceptible, desde el siglo XVIII (Praz 1976: 14-15), habría sido internalizada en las estructuras narrativas modernas a raíz de la expansión mediática -y al menos como se le enuncia, probablemente impensable fuera de ellas-. El caso más claro se habría producido con Flaubert, "whose dispassionate, pitiless gaze has often been compared to that of a photographer or even a filmmaker, with his montage of successive perspectives" (Jay 1993: 111) ${ }^{4}$. Afirmaciones que se han interpretado más osadas, como las de Eisenstein ${ }^{5}$, intentaban localizar toda clase de técnicas y procedimientos cinematográficos en obras literarias anteriores a la aparición del cine -antes que teoría de una literatura precinematográfica (difundida en Francia hacia los años 50) como parte de una herencia, lo que explica la detección de procedimientos cinematográficos en los textos literarios- (Peña-Ardid 1999: 73-75). Parece, entonces, haber mayor fundamento en quienes señalan que el posterior desarrollo del dinamismo visual del cinematógrafo, de su imaginería urbana y eléctrica, de sus rápidas elipsis o de sus diálogos coloquiales o entrecortados llegó, a la inversa, a consolidar las técnicas de escritores como Dos Passos, Hemingway, Faulkner y Hammett (Gubern 2003: 114), además de la escuela francesa del Nouveau Roman.

Incluso hasta un (por ahora) restringido sector de la crítica parece verse remozado con toda una teorización de la mirada que -a raíz de los replanteamientos teóricos de la imagen- ha sido suscitada por el desarrollo de los medios audiovisuales. Eso ayuda a explicar que ensayos pertenecientes propiamente al siglo XX, como el de 1961 de Jean Starobinski, hayan actualizado los tradicionales estudios sobre la literatura francesa de la ilustración desde una lectura de la espectacularización de la mirada que incluye las divagaciones despertadas por lo que se ha conformado como ese perverso deseo de ver -y de ser visto-. Lo propio han hecho otros investigadores como Dorothy Kelly en Telling Glances (1992) -donde examina el voyeurismo en los textos de Balzac y Diderot- y A. C. Spearing -quien remonta aun más lejos el corpus de investigación en su texto The Medieval Poet as Voyeur (1993)-. 
Incluso de novelas más recientes, como Le voyeur (1955) de Alain Robbe-Grillet, Patricia Martínez afirma que "el movimiento de los ojos del narrador es similar al de una cámara que nos devuelve fría y objetivamente la realidad circundante" (en Robbe Grillet 1987: 42) -más o menos por la misma época en que Alexander Astruc hablaba del nuevo cine francés como portador de una cámara stylo (estilográfica)-. Posiblemente parte de esta crítica se desmerecería si se toma en cuenta que, como en el célebre découpage técnique de Paul Leglise sobre el primer canto de la Eneida donde buscaba poner de manifiesto el arte visual de Virgilio, el error ha sido el de "confundir la indiscutible existencia de estilos literarios más o menos 'visuales' o sensibles al problema del movimiento (...) con una supuesta 'premonición' por parte de la literatura de la estética cinematográfica" (Peña-Ardid 1999: 78). Se trata de una correlación analítica cuya enunciación exige la preexistencia -el conocimiento- de instrumentos y procedimientos fílmicos que no sólo se insertan en las prácticas de la cultura visual, sino que se asumen probablemente incluso de forma inadvertida en la praxis interdisciplinar. Todo esto viene a demostrar, en suma, que los usos tradicionalmente no funcionales de la mirada -así como la visualidad en general, según se mencionó- están muy lejos de ser una cuestión moderna, pero es probable que el desarrollo audiovisual, con su desborde de convenciones imaginarias, acarreadas por la mediatización de las sociedades, haya contribuido a su consideración en el campo de los estudios literarios -aunque hasta ahora de manera un tanto tímida- o al menos a un replanteamiento conceptual a la luz del desarrollo de un nuevo lenguaje.

Sin embargo, como en toda generalización, habría casos concretos -propiamente del siglo XX- que participarían, aunque tímidamente, de este influjo, como ocurre con el relato de Allan Poe, The Man of the Crowd (1840), donde la acción (y la reflexión) desencadenante de la sencilla trama viene dada por su protagonista-narrador -mezcla de voyeur y flâneur-, ocioso veedor de un café londinense que se dedica a la observación atenta y hasta persecutoria de los viandantes. Y sólo apenas dos años más tarde de la publicación de Poe se editaría el relato de Cornell Woolrich (seudónimo de William Irish), It Had to Be Murder (1942) -que se popularizó a raíz de la célebre adaptación cinematográfica de Hitchcock-, en coincidencia compartida con la novela del mismo año La fenêtre des Rouet del belga Georges Simenon ${ }^{6}$. En todas estas obras las vidas de los protagonistas se organizan a partir de enfoques y problematizaciones diferentes, siempre desde el tamiz de una mirada que no deja de pertenecer a la furtividad.

De hecho, es innegable que el sentido visual conforma la guía que articula Le voyeur y La jalousie (1957) de Robbe-Grillet, la segunda y tercera de sus novelas -no en vano emparentadas, según la crítica, con la cinematografía-. De carácter puramente fenomenológico, ambas giran en torno al sentido óptico tanto en su estructura como en unos personajes voraces de imágenes. En el caso de La Jaulosie desde la mirada de un marido invadido por los celos (jalousies) que -con la frialdad de una cámara fotográfica contrastante con un deleite que oscila entre lo enfermizo y lo mórbido ante la contemplación de una invariable escena- espía a través de las celosías (jalousies) a su esposa acompañada de otro -no es gratuito que el mismo término en francés también se utilice para referirse al amor inquieto-. Dado, empero, la insuficiencia del sentido para una percepción más integral, la descripción debe recurrir al despliegue del delirio para suplir las limitaciones (básicamente acústicas) impuestas por la distancia (la conversación entre ambos, las ocupaciones de ella...). Es una narración que se dispone desde una mirada que detalla una y otra vez, con precisión matemática, una situación que tiene un (contrastante) trasfondo pulsional -al igual que las creaciones a primera vista mecanicistas de Duchamp-. 


\begin{abstract}
[Robbe-Grillet] liga la acción a la 'cámara' de un ojo presente en la novela que desde el interior de la casa observa lo que sucede en la terraza a través de la persiana (...), cuyas hojas a veces se juntan, a veces se separan. Este ojo puede corregir su ángulo de incidencia visual, ya que dispone de varias ventanas, pero jamás abandona el interior estático de la casa, limitándose a satisfacer contemplativamente a sus celos (...). El fenómeno de la visión (...) ha sido desligado así de su unión tridimensional con el espacio y el tiempo lineal, unión sólo anulada en el éxtasis (Pollmann 1974: 232-233).
\end{abstract}

No sería, por tanto, casualidad que en este panorama, dos autores de alcance mundial -Alain Robbe-Grillet y Alberto Moravia- articularan dos de sus novelas con base en el voyeurismo como tendencia (o compulsión) visual, las cuales, ya desde sus respectivos títulos, Le voyeur (1955) y L'uomo che guarda (1985) -que al fin y al cabo convergen en una idea que es la misma-, personalizan la oscura pulsión en sus protagonistas, aunque desde diferentes enfoques: una en el hecho fenomenológico y la otra en las derivaciones eróticas (freudianas) que alcanza como gratificación visual.

\title{
2. Mecanismos de construcción de la novela fenomenológica: Le voyeur
}

A semejanza del arte y a diferencia de la cinematografía, en la práctica literaria el tratamiento de la mirada -y del voyeurismo- no puede considerarse un eje de una misma intensidad o magnitud siquiera comparable -básicamente porque la abstracción de la letra supone una estructuración diferente que la de la visualidad-. En contra del razonamiento que esgrime el protagonista de L'uomo che guarda, no suelen adquirir trascendencia o problematización equivalente -quizá salvo en el género negro- pasajes donde un personaje espíe a otro, dedicando parte del desarrollo en contemplaciones de carácter furtivo -lo que Dodo llama "voyeurismo de un personaje" (2000: 40): más bien es una función asumida por el narrador y, por extensión, por el lector-. Es probable que una poderosa razón que brinde una explicación general a la ausencia de situaciones y/o personajes furtivos resida en que se trata de una actividad asociada más bien a la descripción -cuya pormenorización podría verse como un intento de compensar la falta de visualidad del lenguaje escrito- antes que a la narración propiamente dicha -pues el exceso de visión obnubila la acción-.

\subsection{La tiranía de la significación}

La descripción es uno de los presupuestos básicos que distinguen a la escuela literaria de Nouveau Roman -nominación acuñada por Robbe-Grillet- también conocida bajo el sintomático nombre de L'Ecole du Regard -entre cuyos rasgos preeminentes destaca una observación detenida, estilizada y sobrevalorada (aunque ya no desde la tematización, sino desde su misma construcción narrativa)-. En una primera fase han tomado parte otros novelistas entre los que figuran, con sus indudables y legítimas divergencias, Nathalie Sarraute y Marguerite Duras (esta última dividida, como es sabido, entre la actividad cinematográfica y la narrativa). Los escritores de esta escuela literaria no se mostraban interesados tanto por interpretar la realidad como por describirla, o sea, por dar cuenta de la existencia de una actitud visual desde la inscripción de un espacio en el que interactúan las estructuras trascendentes de la conciencia: "De ahí la primacía de lo visual, de la descripción óptica como forma de captación del mundo objetival", dice Martínez (en Robbe-Grillet 1987: 34). En tanto privilegio de lo visual, la novela se ajusta mayormente al registro visual de objetos que se traducen en el lenguaje literario en la pormenorización que, como el voyeur, se conforma con el gusto de la delectación, sin interposiciones valorativas. 
Georg Lukács argumentaba que en la segunda mitad del siglo XIX la literatura basada en la observación y en la descripción eliminaba siempre en mayor medida el trueque recíproco entre praxis y vida interior, limitándose a las vicisitudes superficiales (1977: 47, 62) -concepto, este último, que introduce la presencia de un elemento específicamente visual-. Sería, de todos modos, difícil encontrar especificación más precisa para Le voyeur, novela que (al igual que fundamentalmente las de 1953 a 1959, esto es, la considerada primera época de su autor) deja de manifiesto el sacrificio de la épica (la narración) a favor de la observación (la descripción). Leo Pollmann sostiene que Mathias, el protagonista, es muy superficial para ser un personaje, que a las cosas les falta la dimensión de profundidad y que el argumento aparece construido alrededor de un espacio hueco (1971: 175): precisamente de lo que se trata es de liberar al ojo -y también al mundo-- de la tiranía de los significados solidificados. "No es esa la función del arte (...)", dice Martínez, "se trata sencillamente (...) de recorrer la superficie de los objetos, respetando su incertidumbre, su inconsistencia metafísica o su angustiosa contundencia” (en Robbe-Grillet 1987: 24). Su autor procede a partir de un vaciamiento de los significantes ${ }^{7}$ para quedarse en la mera puntualización ocular, dejando en evidencia las oquedades de sus estructuras, sin explicaciones (como las psicoanalíticas, tan en boga en aquellos momentos) ni pretensiones de indagación en lo narrado.

Desde las primeras páginas se manifiesta la tendencia a precisar un punto de vista óptico en la descripción de los objetos -que constituye uno de los auténticos aportes del cine a la narrativa (Peña-Ardid 1999: 126) ${ }^{8}$-. Responde a lo que Pollmann categoriza como el intento de escribir una novela puramente ontológica, fenomenológica (1971: 147) desde la violentación de la estructura tradicional ${ }^{9}$ (la sucesión lineal o el principio de continuidad) a través de técnicas experimentales que se llevaron a cabo en un siglo caracterizado, sobre todo durante su primera mitad, por el desarrollo creativo del arte vanguardista.

El mecanismo que Robbe-Grillet sigue recuerda al que en la plástica llegaría a emplear Duchamp: en su instalación Étant donnés..., la situación expuesta aparece desprovista de cualquier referencialidad -ni siquiera a partir de las correspondencias comunes (en el paisaje, el momento del día, los personajes...) que Paz identificaba con uno de los mitos de la Antigüedad Clásica (el baño de Diana y la perdición de Acteón contado por Ovidio) (1998: 129), básicamente porque se trata de un cuerpo privado de geografía facial, de una localización física y de una circunstancia descontextualizada (muy semejante a La Jalousie)-: su significación carece de excedentes, no existe modo de superar lo que está dado a la vista o de desentrañar el sentido -tan sólo es "une superficie sans intérieur, un épiderme sans entrailles, une coque vide, un moule" (Clair 1977: 139)-. Por ello se ha dicho que la mirada de la narración de Robbe-Grillet resulta purificadora. Instituye, como dice Barthes, la nada del objeto, de manera tal que establece una suerte de desgarradora ruptura de la solidaridad entre el hombre y los objetos -cuya resultante es un texto deceptivo, que consiste en defraudar el sentido tradicional del contenido, a fin de purificar las cosas mediante la descripción, sin remitirlas a ninguna trascendencia (1967: 238-239)-. A partir de una voluntad formalizada de ausencia de significación que libera a la obra de toda metafísica y la plantea como "un sistema perfectamente estructurado de significaciones cerradas que no nos remiten a ningún elemento extrínseco al propio texto" (Martínez en Robbe-Grillet 1987: 67), o sea, como una totalidad textual, autorreferencial, la novela se realiza, al igual que el cuadro de Duchamp, en su más pura función antiexpresiva ${ }^{10}$ : por algo decía Lukács que la presencia que proporciona 
la descripción se encuentra en la antípoda exacta del elemento dramático, la más adecuada para describir situaciones estáticas, inmutables, estados de ánimo o naturalezas muertas (1977: 53): las de los protagonistas de Robbe-Grillet.

Lo que ocurre, no obstante, es que la novela carente de sentido que ansiaba Flaubert -de quien es sabida su ambición de escribir un libro sobre nada, un libro en el que las palabras se bastasen a sí mismas, donde el lenguaje demostrara su propia competencia- resulta imposible. Tampoco la imagen visual puede llegar a ser del todo imparcial porque cualquier aproximación a un objeto conlleva siempre un posicionamiento no sólo desde el que se lee, sino desde el que se escribe. Y aunque el mismo Robbe-Grillet llegara a anunciar, en 1963, un cambio en el lenguaje literario, tal vez su posterior dedicación al oficio del cine -cuya materia prima es lo visual, lo externo, en suma, lo superficial- hubiera supuesto el inconfesable reconocimiento de lo que habría confundido con un deseo. De ahí la dificultad de aceptar que Le voyeur sea tan sólo un texto que se agote en la descripción. Sus imágenes se corresponden a una atmósfera en la que se rarifica una contenida dosis de agresividad visual, como la recurrencia del rojo (declarada marca autoral de la violencia pero al mismo tiempo excepcional símbolo del erotismo) en la herrumbre que tiñe el cáncamo de las argollas del muro en el muelle; las uñas crecidas del protagonista, lo que -sumado al desvío del itinerario de la busca de una niña cuya indocilidad es insistentemente remarcada a lo largo del relato ["la desobediencia de los niños que tienen que hacer siempre aquello que se les ha prohibido" (1987: 244)]- recuerda la descartada versión de la historia sobre el cuento infantil de Perrault (1697) (marginando la popularizada por los Grimm); el trozo de cáñamo con que el protagonista maniata a la víctima y que -desde su sintomática descripción en los primeros párrafos ["en perfecto estado, cuidadosamente liado en forma de ocho, con algunas espiras adicionales enrolladas al estrangulamiento del nudo" [énfasis agregado] (Robbe-Grillet 1987: 80)]- trae a su memoria la ominosa preferencia por coleccionar cordeles: imágenes todas que ponen el hincapié en la (irrefrenable) violencia sexual.

Junto con otras representaciones que transcurren a su paso -o más bien, a su vista- y que se organizan a su vez en torno a un mismo motivo (la niña del barco, la actriz del cartel, el maniquí mutilado, la fotografía de Jacqueline: figuras femeninas todas con la cabeza ladeada y los brazos recogidos hacia atrás, en una postura semejante de indefensión -de sujeción-), se revela la obstinación de un deseo imaginariamente visualizado a través de la sucesión metafórica -de remisiones redundantes e incesantes-. Pero lo que esta serie de imágenes fundamentalmente convoca, desde un trayecto espacial que sigue un movimiento octogonal -leitmotiv del texto-, es el acontecimiento desencadenado por la presencia de ese minotauro moderno que, sin esperar la llegada del contingente de donceles atenienses dispuestos a la ofrenda, sale en su busca. De hecho, Le voyeur es una condensación de Le voyageur, según Pollmann, el título originalmente previsto (1971: 173), lo cual inscribe al protagonista en la tradición de étranger -en su doble acepción del término-.

Esta realidad narrativa se articula desde una insistencia de la narración en el ocho como estructura cíclica de repetición, a la vez que -junto con las ruedas de la bicicleta, las argollas del muelle, las formas redondas de los relojes...- consolida la abstracción geométrica elemental, básica de la representación ocular -fórmula gráfica del décalage con circuito doble (Pollmann)-: "Sin embargo, eran unos ojos grises muy ordinarios", se dice en referencia a Julien, el testigo circunstancial del acto, “(...) dos círculos perfectos e inmóviles, situados uno junto al otro y perforados en su centro por un agujero negro" [énfasis agregado] (Robbe-Grillet 1987: 268). La reiteración de esta figura geométrica hasta en el mismo recorrido logístico de 
Mathias asimismo apunta al argumento circular (autorreferencial). En torno a su itinerario se habrá de producir, como parte de una suerte de ritual cíclico, el (nuevo) sacrificio de una víctima inocente alegorizado bajo la leyenda del monstruo marino- para garantizar su purificación: no es casual que los baptisterios y las pilas bautismales adopten con frecuencia una figura octogonal (Beigbeder 1989: 335).

Según Sturdza, habría un suceso inscriptor -que funcionaría como lo que el psicoanálisis ha denominado la escena primordial o primitiva-, el cual, habiendo sido preservado en el inconsciente, no se elabora en forma de recuerdos, aunque su represión los visibiliza en actos (1974: 30) -más precisamente, en (re)peticiones ${ }^{11}$ : Lacan planteaba que es una escena que resulta traumática porque una de las vías es que el sujeto encuentra en ella demasiado placer (1999: 78)-. Ciertamente se trataría de un advenimiento traumático -irreferido aunque al fin y al cabo, dada la inexpresividad del personaje ${ }^{12}$, no el único-: un acontecimiento "cuyo recuerdo se había quedado reprimido sin ser representado ni elaborado (...) que Mathias será obligado a repetir" (Sturdza 1974: 32) bajo la relación obsesiva de violación y asesinato: he ahí la semejanza fónica entre el título con el término violence (y con el nombre con que este suele confundir a la víctima, Violette) -que asimismo se sugería en el cuadro de Duchamp y se explicitaba en el referido texto de Bataille, Histoire de l'œil-: la violencia es ingrediente del sexo, la esperma tarde o temprano termina convertida en sangre. La línea que lleva el ojo hacia el sexo y luego a la violencia se erige en un estilema en el arte. Pero he aquí que el pasaje en cuestión está elidido por un texto que discurre repetitiva y desorganizadamente entre lo imaginario, lo ficticio y las distintas temporalidades de lo real -que, según Gombrich, había tratado San Agustín "cuando observaba que la mente no sólo retiene la impresión pasada, sino también penetra en el futuro" (2000: 48)-: los intervalos perceptuales se conforman como un flujo que integra memoria inmediata, anticipación y retrospección. Por tanto, la obsesiva voluntad de fijación y exactitud se atempera ante una realidad que el mismo narrador reconoce engañosa, como no sin sorna lo explicita en su desconfianza por "las representaciones precisas pero falsas" (Robbe-Grillet 1987: 95): una mezcla de dimensiones consonante con lo que Pollmann llama "un ver de un modo múltiple" (1971: 173).

\subsection{El mirón embaucado}

La narrativa robegrilletiana puede definirse entonces desde una “[d]esintegración de la anécdota y del tiempo, desmitificación del héroe y del tema, inquietante relevancia de las cosas, todo ello referido por una mirada aséptica y neutral que describe con exactitud geométrica la realidad que contempla" (Martínez en Robbe-Grillet 1987: 42). Entendida como indiscreción íntima, la mirada voyeur partiría de un criterio metonímico -el ojo acoplado a un sistema mayor (el cuerpo) que a su vez se conecta a unos impulsos escopofílicos y sexuales-. Este criterio sería ampliable no sólo a los filmes intimistas, como propondría Truffaut (1991: 179) en la célebre entrevista a Hitchcock, sino a cualquier narrativa de cualquier género -en un sentido afín al que más tarde sugiere Moravia en su mencionada novela: por eso la generalización que Dodo, el personaje principal, hace bajo lo que llama voyeurismo del escritor tiene mayores asideros que la del personaje, no siempre ni necesario observador contumaz-.

Lo anterior podría objetarse volviendo a la condición exhibicionista que soporta toda obra de arte -ilustrada en la composición de Duchamp-, que da a conocer sólo lo que su autor quiere mostrar ${ }^{13}$. Esta proposición a favor del exhibicionismo en el arte (como planteaba Étant donnés... de Duchamp) desarticula el voyeurismo, y la novela de Robbe-Grillet deja 
precisamente en evidencia esta escisión. La omisión -uno de los décalages, para Pollmannzanja una partición en el fluir narrativo, un vacío en la historia que estimula la conciencia de la connatural avidez, en contraste con buena parte de los textos literarios que suprimen o rebajan el componente mórbido de una actividad formulada durante mucho tiempo como elevada, más bien excelsa, y promocionan, en cambio, el acto de escritura-lectura desde su operación opuesta, esto es, como actividad catártica y humanizante. Por el contrario, la literatura, suscribiendo las palabras de Trías, necesita de un velado componente siniestro que le inyecte vitalidad (1982: 42).

Así las cosas, no resulta infrecuente que "el lector durante la lectura se fusion[e] con el narrador al introducirse en el mundo que éste le propone, al participar de la visualidad de su escenario, al compartir una misma visión" (Català 2000: 113), pero el de esta novela inopinadamente se ausenta -o mejor, es excluido- del clímax del relato, o sea, del pasaje resolutorio del itinerario de Mathias: aquel en donde tiene lugar el acto definitivo para su propio solaz $^{14}$-y de paso para Julien, el testigo incidental-: la violación y asesinato de Jacqueline -lo que hace alusión a la fundacional distinción platónica entre mímesis y diégesis que con una diferencia de siglos Henry James reactualizara bajo los conceptos de showing y telling (equivalente a la distinción de Lukács entre narrar y describir)-. Tal elisión, que termina de cerrar el bucle del viaje, hace del voyeurismo del lector una expectativa inacabada, un acto frustrado -porque los pormenores giran en torno al rodeo pero no al encuentro, detallan el itinerario pero no el suceso-. Este movimiento, que adquiere la forma del (repetido) signo del ocho -tradicional símbolo del equilibrio y de la justicia (Chevalier y Gheerbrant 1988: 768) que "en el particular evento de su retorno" al decir de Foucault, adquiriría un sentido mordaz-, se representa en el trayecto espacial por la isla: la impostura finalmente se ha cumplido.

$\mathrm{Y}$ es que el narrador se encarga de asegurar que el propio lector, que observa lo que vive -y vive lo que observa- Mathias, no pueda servir de testigo porque el protagonista cuenta, aparte de Julien, con un valioso cómplice que acalla el crimen -y que, al mismo tiempo, desarticula el inconfesado miedo del personaje por el aciago doble círculo (doble crimen) figurado en sus muñecas esposadas-. Un cómplice que se encarna en la figura del narrador omnisciente: tras la noticia del descubrimiento del cuerpo de la pequeña pastora, camufla su discurso con el del marino que participa en su descubrimiento para barajar varias posibilidades sobre las circunstancias que acontecieron en su muerte, como si -farsante- lo ignorase. Un cómplice que, antes bien, se ha desempeñado como el ojo impertérrito y omnipresente, no de un dios cuyos efectos -la justicia poética, por ejemplo- se hagan manifiestos, sino de la siempre misma gaviota con el que se funde: "[e]l ojo redondo inexpresivo (...), el ojo inmutable espiaba, semejante a los ojos sin párpados de los peces, como si una insensibilidad absoluta le librase de todo parpadeo" (Robbe-Grillet 1987: 259), limitado a ser nada más que un ojo: el de un cómplice que atestigua una y otra vez el hecho desde una distancia no sólo física, sino indecible: el texto -el mayor y el más cabal de los voyeur- ${ }^{15}$.

\section{El voyeurismo según Dodo: L'uomo che guarda}

Permitiéndose una digresión metalingüística, Alberto Moravia inicia el segundo capítulo de su novela -entre las menos destacables-L'uomo che guarda con un apartado en el que suspende la recién iniciada acción dramática. En él, su protagonista, Dodo, un joven profesor de literatura francesa, formaliza una reflexión sobre el voyeurismo, donde introduce un par de condiciones sine qua non para que, tal y como lo concibe, tenga lugar. 
La primera estipulación consiste en atribuirle la existencia de movimiento: "el voyeurismo empieza por la observación del movimiento del objeto espiado" (Moravia 2002: 42) ${ }^{16}$. Dodo hace del voyeurismo fuente de artes como la narrativa, área de oficio -quizá la contribución más notable a la teoría de la literatura: "Por lo tanto, cuando un novelista describe a dos personajes en el momento de su acoplamiento, en realidad mira y hace que nosotros miremos por un imaginario ojo de la cerradura" (Moravia 2002: 40)- y, desde luego, la cinematografía, cuyo fundamento da trámite a su existencia. El personaje sostiene su argumentación afirmando que ni la pintura ni la escultura pueden ser fuente de esta compulsión visual "porque (...) falta movimiento: el voyeur no espía tanto el objeto como su movimiento, es decir, su comportamiento" (Moravia 2002: 39) (en última instancia, el tiempo). Esta observación es refutable si se considera que el arte griego había creado, a partir de una elevada inestabilidad de sus figuras, mecanismos que compensaban la ausencia de movimiento (Gombrich 2000: 83). Quizá merezca apuntarse que la premisa de que estas artes (junto con la fotografía o el grabado, omitidas por el personaje) se configuren desde la puesta de imágenes no temporalizadas -a diferencia del cine, cuya sucesión se registra en un espacio-duración (Deleuze)- no significa que estén desprovistas de medios para representar el fluir del tiempo: basta reparar, por ejemplo, en el detalle del efecto estroboscópico del torno de Las hilanderas (1856-1858) de Diego Velázquez o las adiciones no literales (como rayas o miembros duplicados) popularizadas en las figuras de los tebeos para sugerir movimiento. Pero más ampliamente,

\footnotetext{
[1]as imágenes, todas las imágenes, son temporales, ya sea porque incorporen la duración a través del movimiento o porque expresen distintas capas de la memoria; ya sea porque propongan una prolongación de sí mismas en otras imágenes relacionadas o porque la visión del espectador las lleve a establecer relaciones insospechadas con el entorno (Català 2005: 49-50).
}

La exclusión, por tanto, del voyeurismo en las mencionadas expresiones artísticas, supone una concepción ahistórica y limitada del funcionamiento general de la mirada.

La otra condición identificada por Dodo es el conocimiento de observar un proceder íntimo en el espectador: "debe tratarse de un comportamiento tan íntimo que nadie, excepto el voyeur, podría espiar sin ser consciente de cometer una indiscreción" [énfasis agregado] (Moravia 2002: 39). De nuevo, lo debatible de la apreciación surge ante la negación de uno de los elementos que conforman la naturaleza del fenómeno voyeur: su carácter pulsional, la reacción (visual) instintiva -sin que deba necesariamente estar intervenido por una mediación de la conciencia-.

Hechas las precisiones convenientes, Dodo agrega unos incisos narrativos -para complementar la (ya matizada) presencia de este tipo de mirada en la literatura universal- que dan pie a una amplia disertación teórica -a través del cuasi olvido o la suspensión dramática de la acción iniciada- bajo el recurso diegético de la actividad pedagógica de su protagonista. En ella procede a la transcripción completa de la referida composición de Mallarmé "Une nêgresse...." Al poema en cuestión le sigue un didáctico y detallado comentario en el que no faltan las preguntas retóricas -propias de la oratoria docente- y valoraciones personales -como que pertenece "al género comúnmente denominado obsceno" (Moravia 2002: 41) por "la forma de presentar la escena” (Moravia 2002: 44)-, las cuales responden, más que a una hermenéutica sustentada, a falacias y a efectos de lectura.

No es, por tanto, gratuito que la historiografía literaria advirtiera el decaimiento de la etapa final del novelista, de quien se llegó a aducir "la incapacidad [...] de soportar el peso de los debates teóricos con los que cada vez se enfrenta, y de traducirlos en formas literarias 
de carácter narrativo" (Petronio 1990: 994). La crítica literaria coincide en destacar el temple moral de la obra -una de las últimas- de Moravia: ciertamente, algunos han visto al escritor como un moralista en el sentido francés del término, es decir, como un analista de costumbres que se sitúa frente a la realidad humana y la escruta con fría atención (Petronio 1990: 991). Su narrativa, para otros como Sapegno, se define por el uso de técnicas de la descripción y/o de la actividad gráfica: "Una tendencia moral, pero no moralista, a retratar los aspectos desesperados y corrompidos de la vida y de las costumbres actuales..." [énfasis agregado] (1964: 640). Es probable que esta preocupación por la dimensión social llegara a expresarse de alguna manera en su personal forma de narración, definitivamente continuadora de los procedimientos de representación clásica, en declarada contraposición con las preocupaciones rupturistas de su colega francés, cuyo apego a los hechos de un modo, por el contrario, frío y desapegado -ya se dijo: sólo descritos- ni siquiera permite sugerir una justificación de las acciones del personaje. Más interesado por la innovación formalista de la novela moderna, Robbe-Grillet no escatimaba recursos estilísticos destinados a la referencialidad múltiple de los signos (Jacqueline-Violette) o a la creación de signos sin referente (Jean Robin).

El único punto común de ambos textos reside en la concurrencia de un fenómeno cuyo tratamiento no lo hace parecer el mismo ni aun en el eje que articula los acontecimientos -la mirada-, porque la anécdota de L'uomo che guarda se inscribe con mayor voluntariedad en la tradición literaria que no niega la referencialidad del signo. Quizá la distancia más importante radique en que la ávida mirada del protagonista no insiste esta vez en una divagación errante de los objetos externos, sino en una observación detenida de las actitudes y conductas, de las emociones y deseos (en especial eróticos ${ }^{17}$ ) que reproduce una circunstancia rotundamente edípica. Así, la situación descrita tiene más que claros visos en las consecuencias de la observación de la escena primordial o primitiva: la turbadora e involuntaria coyuntura que de pequeño Dodo logra entrever -un momento de intimidad sexual entre sus padres-. Esta imagen, que asimila como denigrante para su madre ${ }^{18}$, produce en él una herida que obstruye posteriores relaciones convencionales.

La presencia de esta escena supone, como es de esperar, una visión/acción determinante, porque formaliza el deseo hacia la madre, que tendría su continuidad en el desarrollo de la compulsión escópica del personaje. Pero al mismo tiempo plantea el desafío hacia el padre: esta construcción metafórica adoptada por el metalenguaje psicoanalítico como forma de representación de la Ley viene a ser literal -por eso el modo de apelación opera mediante las no menos autoritarias (in)nominaciones de padre y profesor-. Hay entre ambos personajes un enfrentamiento tácito que se inaugura formalmente con la escena primordial y se prolonga hasta la etapa adulta en la ambigua relación que el padre sostiene con la esposa de Dodo. El síntoma más claro de esta rivalidad es el presuntuoso despliegue de su falo -más que de su pene ${ }^{19}$-. Ya se ha aludido al tabú bíblico fundacional que se relaciona con la visión de los genitales del progenitor, donde el carácter de prohibición viene dado no por el hecho de que la mirada suponga una apropiación de poder, sino porque el acto de percepción aniquila y cuestiona -lo que es susceptible de interpretarse como una desestabilización del dominio fálico- (Van Alphen en Bryson et al. 1994: 267-269). La diferencia es que en la novela la interdicción es transgredida por el mismo padre -que se exhibe-, como si al demandar la mirada del hijo pretendiese ratificar un estatus de superioridad que aquel, sin embargo, nunca se ha atrevido a cuestionar. 
El conflicto propiamente se remonta a la infancia del personaje, donde la actitud hacia el padre se define dual, ambivalente -basado en la posesión de la madre y la encarnación de la Ley-, como refiere Bryson en términos generales: "while he is enjoined to be like the father, he cannot and must not be like the father in one crucial respect, namely that he cannot possess the father's sexual privilege and power" (en Bryson et al. 1994: 233). El replanteamiento de Silverman interpreta el fenómeno edípico al mismo tiempo que lleva a dilucidar su caso a partir del distanciamiento con el padre (la Ley) que enfatiza Moravia, probablemente con más claridad por tratarse de una elaboración ficcional, a raíz de la rivalidad fálica -como se concreta, más allá del acto de exposición del miembro, en la competencia por la posesión de objetos tanto en la infancia como en la vida adulta: sellos, mujeres-. El padre pervive como rival en tanto se interpone en la identificación de su hijo con la imagen materna, la figura de originaria identificación (la cual como todo objeto de deseo, es elusivo, ausente -y que, desde la demanda, se torna aprehensible sólo mediante la mirada-).

Lo que L'uomo che guarda sostiene es que el auténtico foco de conflicto ha residido desde siempre en la construcción de un complejo vínculo paterno-filial. Más allá, empero, de la presencia del intertexto psicoanalítico -manipulado, artificioso, incluso hasta por momentos forzado-, las preocupaciones del protagonista, esa especie de outsider burgués, giran, más ampliamente, en torno a una comunicación en crisis que parte del propio seno familiar -y se resuelve ahí mismo-.

\section{Cierre}

La tematización de lo visual en la literatura puede estar vinculada a una técnica descriptiva absorbida por la conciencia experimental moderna -cuyas bases habrían de remontarse a los inicios de la propia articulación visual (el daguerrotipo y la fotografía)-. Así lo había sugerido Susan Sontag, cuando apuntaba que, desde Apollinaire, Eliot, Pound y Williams -correspondientes a la generación de principios del siglo XX-, la poesía se había venido definiendo más por un interés visual (1992: 106). No obstante, la dirección aquí recorre un sentido semejante al que había propuesto Català: desde hace más de un siglo la narración literaria incorpora funciones de la imagen que amplían las instancias narrativas del texto (2000: 114). Lo que, en suma, no deja de resultar significativo es que no sea sino en este preciso momento de la contemporaneidad -de irrupción de imágenes, de predominio y consumo cotidiano y caótico de lo visual- cuando se producen resonancias directas aun en una práctica cuya mediación (del lenguaje) es proclive a elucubraciones y abstracciones que se prestan para trascender el carácter superficial que la tradición le ha atribuido a lo visual. A partir de entonces y con más fuerza que nunca, el imaginario visual se habrá de traslucir con mayor densidad en la creación literaria sucesiva y sobre todo en la lectura contemporánea de textos anteriores al siglo XX.

\section{Notas}

1. Cuya mirada está, como dice Denzin, unida a los intereses del estado y su protección: "In its most powerful form this was the gaze of the police state, the gaze of the agent of the police, the detective. This inspectig agent then utilized the scientific gaze of other surveillance experts in his or her work" (1995: 51). 
2. Precisamente así lo evidencia el thriller de Stephen Hopkins, Under Suspicion (2000), que aporta un elemento interesante a su primera versión, Garde à vue (1981) de Claude Miller. Cuando el filme -que trata sobre la investigación de las extrañas circunstancias que rodearon el asesinato y violación de dos niñas desvinculadas entre sí- procede a la reconstrucción visual de los testimonios en flash-back (tanto de los testigos como del mismo imputado), el inspector que sigue el caso - con una obsesión que raya en lo personal-, se infiltra físicamente en las imágenes del relato -hechas de recuerdo y/o de invención, las cuales pertenecen estrictamente a una intimidad vivida por otros-para preguntar, conminar, comentar, $\mathrm{y}$, sobre todo, para mirar.

3. 'Pero había que esperar la literatura 'abyecta' del siglo XX (aquella que continúa el apocalipsis y el carnaval) para comprender que la trama narrativa es una delgada película constantemente amenazada por el estallido. Pues cuando la identidad narrada es insostenible, cuando la frontera sujeto/objeto se quebranta, y cuando incluso el límite entre el adentro y el afuera se torna incierto, el relato es el primer interpelado. Si a pesar de ello continúa, cambia su factura: su linealidad se quiebra, procede por estallidos, enigmas, abreviaturas, incompletudes, enredos, cortes..." (Kristeva 2000: 185).

4. Habría también que considerar que, por influencia de la dramaturgia, la novela estaba en ese entonces estructurada escenográficamente -como constatará finalmente Henry James, calificado como el prototipo de novelista que basaba sus relatos en una concepción escénica- (Català 2001: 111-113).

5. "Hay escritores que escriben, diría yo, directamente en forma cinematográfica. Ellos ven en 'fotogramas'. Más aún, en imágenes de fotogramas. Y escriben en forma de guión de montaje. Unos ven en forma de guión de montaje. Otros desarrollan hechos. Otros componen con metáforas cinematográficas. Algunos poseen todos los caracteres juntos. Por ejemplo, Zola. Zola ve corporizando las cosas. Escribe con gente, con ventanas, con sombras, con temperaturas..." (Eisenstein 1982: 11). En otro de sus ensayos, el cineasta ruso expone cómo los procedimientos narrativos de Dickens fueron asimilados por D. W. Griffith en su elaboración de un modelo narrativo, aunque él mismo deja claro que no hay que llevar demasiado lejos las analogías de rasgos comunes (en Peña-Ardid 1999: 75-76).

6. Simenon es conocido por su fecunda producción en la novela policíaca -los casos del detective Maigret-: un género que se asienta, como en la dinámica voyeur, en la observación detallada y obsesiva. La figura del detective (en inglés, 'private eye') surge en un relato de Poe: el caballero Daupin del relato La carta robada, que luego glosará Lacan en relación con la mirada -narraciones en las que esta se articula como instrumento en la consecución de la verdad-.

7. Pollmann lo explica a partir de una de las imágenes: "Así por ejemplo en el caso de Robbe-Grillet flota en el agua un paquete azul de tabaco de un modo 'carente de significado' respecto a una intervención humanizante (...), mientras que en una novela tradicional no sería pensable un tal paquete de tabaco más que como suciedad al borde del camino, como mercancía en una tienda o como una cosa utilizada para mi servicio, es decir, abierta y vuelta a meter en el bolsillo" (1971: 176-177).

8. En tanto tendencia visual, sin confundirse con el uso de ciertas técnicas cinematográficas como lo hace Martínez: "desde recursos relativamente simples, como primeros planos, aislamiento de lo singular o imágenes yacentes en sí mismas, hasta elementos más sofisticados -un objeto sirve de bisagra entre una escena y otra-, flash back y flash forward" (en Robbe-Grillet 1987: 38). Incluso cuando ciertas construcciones exclusivamente cinematográficas tuvieran cabida en una obra literaria, no poseen la misma función, y más que traslado de un lenguaje a otro, resultan reflejos deformados (Urrutia en Peña-Ardid 1999: 122-123).

9. El relato de uno de los personajes secundarios - que trae la noticia del descubrimiento y estado del cadáver de la pastora- es irónicamente valorado por el mismo narrador en el sentido de que la construcción de la novela sigue una estructura similar: "El hombre hablaba despacio y con una cierta voluntad de precisión, facilitando -aunque en un orden muchas veces poco lógico- todos los detalles materiales necesarios" (énfasis agregado) (Robbe-Grillet 1987: 232). 
10. Para La Polla, tal rasgo marca una característica del cine moderno de Hitchcock que lo emparenta con le Nouveau Roman, donde si bien hace girar la acción en torno al protagonista, la interpretación queda reducida al registro de la cámara, que es la que crea las relaciones mentales (en Castro de Paz 2000: 118).

11. Sin duda la más importante, tal supresión corresponde al ámbito de la conciencia del personaje: se manifiesta como faltas de memoria, signos de su propia represión: "Él no repite porque reprime, reprime porque repite, porque no puede vivir o revivir el acontecimiento pasado de otro modo que en forma de repetición" (Sturdza 1974: 36).

12. Este tipo de personaje tiene sus antecedentes en el modelo que Vanoye destaca de los guiones franceses de los años 20 donde se trataba de rechazar los modelos teatrales y novelescos, sin una carga psicológica o sociológica demasiado afirmada. El resultado es "un cuerpo, una voz incolora, un rostro inexpresivo y unos gestos inescrutables. Actúa poco -incluso nada en absoluto- y pasa de un estado a otro sin que se subrayen las relaciones de causa-efecto que motivan sus cambios o ausencia de cambios" (1996: 57).

13. Como lo propone Lubbock: "el arte de la ficción comienza sólo cuando el novelista considera su historia como un objeto que mostrar, que exhibir de tal modo que se cuente a sí mismo" (en Genette 1989: 263).

14. Que, salvando cualquier distancia, vincula la representación del cuerpo femenino en el filme de Ichikawa (Kagi), donde la imagen del desnudo está vedada al espectador y se mantiene para consumo exclusivo de los protagonistas varones -ni siquiera de la hija cuando atisba la escena-.

15. Propio de le Nouveau Roman, este distanciamiento reafirma la tesis que Nathalie Sarraute expone en su colección de ensayos La era del recelo: ensayos sobre la novela (L'Ére du soupçon, 1956), en el que plantea la pérdida de confianza entre el lector y el autor como un giro a la novela tradicional, lejos de una entrega sin condiciones.

16. Inquietud (que no condición) compartida, aunque desde luego bajo otro énfasis, con la de Robbe-Grillet, quien, en una entrevista citada por Martínez, había afirmado su interés no por los objetos como por el movimiento de la descripción (en Robbe-Grillet 1987: 39).

17. Podría ser que la marcada presencia del erotismo - la exasperación del tema del sexo, central y casi obsesivo en Moravia desde Los indiferentes (Gli indifferenti, 1929), su primera novela-, con apelaciones directas a los genitales y descripciones más o menos pormenorizadas de encuentros sexuales, hubiera influido para que, en 1993, Tinto Brass se animara a realizar la adaptación fílmica del mismo nombre, manteniendo parlamentos enteros de los personajes aunque combinándolos con las lógicas modificaciones que impone el género hard-core, característico en la filmografía del provocador director.

18. Interpretación que no es, por lo demás, inusual en la etapa infantil: en su análisis del caso del "hombre lobo", Freud determinó que el niño interpreta la visión del acto sexual de los padres como una agresión paterna a la madre, además de ocasionar excitación sexual, lo cual es frecuentemente asociado con el peligro y la ansiedad.

19. A partir del basamento antropológico de Lévi-Strauss posteriormente enriquecido por Lacan, hay un complejo reconocimiento entre falo y pene del que basta con simplificar que el primero recurre a la forma del órgano genital (el pene), para simbolizarse como fuente emanadora de poder y privilegios.

20. Lo que por su parte permite una digresión a las palabras de Mirzoeff, para el cual no se trata de una dependencia "de las imágenes en sí mismas, sino de la tendencia moderna a plasmar en imágenes o visualizar la existencia” (2003: 39). 


\section{Bibliografía}

Barthes, Roland. 1967. Ensayos críticos. Barcelona: Seix Barral.

Bataille, Georges. 2003. Historia del ojo. $8^{\mathrm{a}}$ ed. Barcelona: Tusquets.

Bryson, Norman et al. (eds.). 1994. Visual Culture. Images and Interpretations. Hanover London: Wesleyan University Press.

Castro de Paz, José Luis. 2000. Alfred Hitchcock. Madrid: Cátedra.

Català Domènech, Josep Maria. 1997. Elogio de la paranoia. San Sebastián: Fundación Kutxa. 2000. "Ut poesis pictura". Anàlisi. (25): 109-128.

2001. La puesta en imágenes. Barcelona: Paidós.

2005. La imagen compleja. La fenomenología de las imágenes en la era de la cultura visual. Bellaterra: Universitat Autònoma de Barcelona.

Chevalier, Jean y Gheerbrant, Alain. 1988. Diccionario de los símbolos. Barcelona: Herder.

Chillón, Albert. 1999. Literatura y periodismo. Una tradición de relaciones promiscuas. Barcelona - València: Universitat Autònoma de Barcelona / Publicacions de la Universitat Jaume I / Universitat de Valencia.

Clair, Jean (dir.). 1977. Marcel Duchamp. Catalogue raisonné. Paris: Centre National d'Art et de Culture Georges Pompidou.

Denzin, Norman K. 1995. The Cinematic Society. The Voyeur's Gaze. London - Thousand Oaks - New Delhi: Sage.

Eisenstein, Serguei. 1982. Cinematismo. Buenos Aires: Domingo Cortizo.

Fanés, Fèlix. 1985. "Història de l'ull: de Redon a Duchamp". Saber. 2 (març-abril): 24-33.

Genette, Gérard. 1989. Figuras III. Barcelona: Lumen.

Gombrich, E. H. 2000. La imagen y el ojo. Nuevos estudios sobre la psicología de la representación pictórica. Madrid: Debate.

Gubern, Román. 2003. Del bisonte a la realidad virtual. $3^{\mathrm{a}}$ ed. Barcelona: Anagrama. 
Jay, Martin. 1993. Downcast Eyes. The Denigration of Vision in Twentieth-Century French Thought. Berkeley - Los Angeles - London: University of California Press.

Kelly, Dorothy. 1992. Telling Glances: Voyeurism in the French Novel. New Jersey: Rutgers University Press.

Kristeva, Julia. 2000. Poderes de la perversión. $4^{\mathrm{a}}$ ed. México: Siglo XXI.

Lacan, Jacques. 1981. Seminario 1: Los escritos técnicos de Freud. Barcelona: Paidós.

1999. Seminario 11: Los cuatro conceptos fundamentales del psicoanálisis. Argentina: Paidós.

Lukács, Georg et al. 1977. Literatura y sociedad. Buenos Aires: Centro Editor de América Latina.

Mallarmé, Stéphane. 1979. Obra Completa (I). Barcelona: Ediciones 29.

Mirzoeff, Nicholas. 2003. Una introducción a la cultura visual. Barcelona: Piados.

Moravia, Alberto. 1985. Los indiferentes. Barcelona: Orbis.

2002. El hombre que mira. Barcelona: De Bolsillo.

Paz, Octavio. 1998. Apariencia desnuda. La obra de Marcel Duchamp. Madrid: Alianza.

Peña-Ardid, Carmen. 1999. Literatura y cine. Una aproximación comparativa. $3^{\mathrm{a}}$ ed. Madrid: Cátedra.

Petronio, Giuseppe. 1990. Historia de la literatura italiana. Madrid: Cátedra.

Poe, Edgar Allan. 1984. Poetry and Tales. United States of America: The Library of America.

Pollmann, Leo. 1971. La “nueva novela” en Francia y en Iberoamérica. Madrid: Gredos.

Praz, Mario. 1976. Mnemosina: paralelo entre la literatura y las artes visuales. Caracas: Monte Avila.

Robbe-Grillet, Alain. 1970. La celosía. Barcelona: Barral.

1973. Por una novela nueva. Barcelona: Seix Barral.

1987. El mirón. Madrid: Cátedra. 
Sarraute, Nathalie. 1967. La era del recelo: ensayos sobre la novela. Madrid: Guadarrama.

Sapegno, Natalino. 1964. Historia de la literatura italiana. Barcelona: Labor.

Silverman, Kaja. 1988. The Acoustic Mirror. The Female Voice in Psychoanalysis and Cinema. Bloomington - Indianapolis: Indiana University Press.

Simenon, Georges. 1997. La mirada indiscreta. Barcelona: Tusquets.

Sontag, Susan. 1992. Sobre la fotografía. Barcelona: Edhasa.

Spearing, A. C. 1993. The Medieval Poet as Voyeur. Cambridge: Cambridge University Press.

Starobinski, Jean. 2002. El ojo vivo. Valladolid: Cuatro.

Sturdza, Paltin. 1974. "Le Voyeur: viaje en el fondo de la repetición”. Revista de Occidente. 133 (abril): 29-38.

Trías, Eugenio. 1982. Lo bello y lo siniestro. Barcelona: Seix Barral.

Truffaut, François. 1991. Hitchcock. Madrid: Akal.

Vanoye, Francis. 1996. Guiones modelo y modelos de guión. Argumentos clásicos y modernos en el cine. Barcelona: Paidós.

Woolrich, Cornell. 1973. La ventana indiscreta y otras narraciones. Barcelona: Acervo.

\section{Filmografía}

Brass, Tinto. 1993. El hombre que mira (L'uomo che guarda). Italia: Vella Vision, color, 102 min.

Hopkins, Stepeh. 2000. Bajo sospecha (Under Suspicion). Estados Unidos: Revelations Entertainment / TF1 International, color, $110 \mathrm{~min}$.

Ichikawa, Kon. 1959. Extraña obsesión (Kagi). Japón: Avain Film, color, 107 min.

Miller, Claude. 1981. Arresto preventivo (Garde à vue). Francia: Milan, color, 87 min. 